\title{
Levofloxacin-induced life-threatening hypoglycemia in a type 2 diabetic patient with ST-segment elevation myocardial infarction and community-acquired pneumonia
}

\section{ABSTRACT}

Levofloxacin is a broad-spectrum, third-generation fluoroquinolone antibiotic used in the treatment of respiratory and urinary tract infections. Although it is usually well-tolerated, it may cause life-threatening adverse effects, including severe hypoglycemia. We present a case of levofloxacin-induced life-threatening hypoglycemia in a 87-year-old type 2 diabetic patient with ST-segment elevation myocardial infarction and community-acquired pneumonia. Hypoglycemia secondary to levofloxacin is a rare complication $(<0,1 \%)$, but can be more common among elderly patients, with type 2 diabetes (especially treated with hypoglycemic drugs) or renal dysfunction. Our patient was at high risk due to age, diabetes and chronic kidney disease (creatinine $149 \mu \mathrm{mol} / \mathrm{L}$, estimated glomerular filtration rate $27 \mathrm{~mL} / \mathrm{min} / 1.73 \mathrm{~m}^{2}$ ). In the Naranjo probability scale, the patient scored 5 points, which indicates that hypoglycemia was a probable levofloxacin-related adverse effect. In conclusion, we suggest that levofloxacin

Address for correspondence:

Paweł Rostoff M.D., Ph.D.

Department of Coronary Disease and Heart Failure

Institute of Cardiology

Jagiellonian University Medical College

The John Paul II Hospital

ul. Pradnicka 80, 31-202 Kraków

Phone: (+48) 1261422 18, fax: (+48) 126142219

e-mail: pawel.rostoff@uj.edu.pl

Clinical Diabetology 2020, 9, 2, 141-143

DOI: $10.5603 /$ DK.2020.0011

Received: 04.12.2019

Accepted: 02.03.2020 should be used with greater caution, particularly in patients at increased risk of hypoglycemia. (Clin Diabetol 2020; 9; 2: 141-143)

Key words: type 2 diabetes mellitus, ST-segment elevation myocardial infarction, hypoglycemia, levofloxacin, fluoroquinolone

\section{Introduction}

Levofloxacin is a broad-spectrum, third-generation fluoroquinolone antibiotic used in the treatment of respiratory and urinary tract infections [1-3]. Although it is usually well-tolerated, it may cause life-threatening adverse effects, including severe hypoglycemia [2-7].

\section{Case presentation}

An 87-year-old woman, a heavy smoker, with well-controlled type 2 diabetes (treated with glimepiride $2 \mathrm{mg} / \mathrm{d}$ ), chronic kidney disease, arterial hypertension, hyperlipidemia, hyperthyroidism (treated with methimazole $20 \mathrm{mg} / \mathrm{d}$ ), with frailty syndrome and chronic obstructive pulmonary disease, was admitted to the hospital due to acute anterior ST-segment elevation myocardial infarction (STEMI). On admission, the glycated hemoglobin $\left(\mathrm{HbA}_{1 \mathrm{c}}\right.$ ) level was 5.5\% (37 mmol/ $/ \mathrm{mol}$ ), circulating thyrotropin (TSH) was 0.802 (normal: 0.270-4.200) $\mu \mathrm{IU} / \mathrm{mL}$, free triiodothyronine (fT3) was 4.34 (normal: $3.10-6.80$ ) $\mathrm{pmol} / \mathrm{L}$ and free thyroxine (fT4) was 15.95 (normal: 12.00-22.00) pmol/L. Serum creatinine concentration and estimated glomerular filtration rate (eGFR) were $168 \mu \mathrm{mol} / \mathrm{L}$ and $23 \mathrm{ml} /$ 
Table 1. Naranjo Adverse Drug Reaction (ADR) Probability Scale [2]

\begin{tabular}{|c|c|c|c|c|}
\hline Question & Yes & No & $\begin{array}{l}\text { Do not } \\
\text { know }\end{array}$ & $\begin{array}{l}\text { Score in the } \\
\text { presented patient }\end{array}$ \\
\hline Are there previous conclusive reports on this reaction? & +1 & 0 & 0 & +1 \\
\hline Did the adverse event appear after the suspected drug was administered? & +2 & -1 & 0 & +2 \\
\hline $\begin{array}{l}\text { Did the adverse reaction improve when the drug was discontinued } \\
\text { or a specific antagonist was administered? }\end{array}$ & +1 & 0 & 0 & +1 \\
\hline Did the adverse reaction reappear when the drug was readministered? & +2 & -1 & 0 & 0 \\
\hline $\begin{array}{l}\text { Are there alternative causes (other than the drug) that could on their own } \\
\text { have caused the reaction? }\end{array}$ & -1 & +2 & 0 & 0 \\
\hline Did the reaction reappear when a placebo was given? & -1 & +1 & 0 & 0 \\
\hline $\begin{array}{l}\text { Was the drug detected in the blood (or other fluids) in concentrations known } \\
\text { to be toxic? }\end{array}$ & +1 & 0 & 0 & 0 \\
\hline $\begin{array}{l}\text { Was the reaction more severe when the dose was increased, or less severe } \\
\text { when the dose was decreased? }\end{array}$ & +1 & 0 & 0 & 0 \\
\hline $\begin{array}{l}\text { Did the patient have a similar reaction to the same or similar drugs in any } \\
\text { previous exposure? }\end{array}$ & +1 & 0 & 0 & 0 \\
\hline \multirow[t]{2}{*}{ Was the adverse event confirmed by any objective evidence? } & +1 & 0 & 0 & +1 \\
\hline & & & & Total score: $\mathbf{5}$ \\
\hline
\end{tabular}

Scoring: $\geq 9$ = definite $A D R ; 5-8=$ probable $A D R ; 1-4=$ possible $A D R ; 0=$ doubtful $A D R$

$/ \mathrm{min} / 1.73 \mathrm{~m}^{2}$, respectively. Fasting blood glucose levels were between 80 and $140 \mathrm{mg} / \mathrm{dL}$ and less than $180 \mathrm{mg} / \mathrm{dL}$ two hours after meal.

Urgent coronary angiography revealed subtotal proximal left anterior descending coronary artery stenosis and primary percutaneous angioplasty with drug-eluting stent implantation was immediately performed. On admission, the patient was diagnosed with community-acquired pneumonia and antibiotic treatment with ceftriaxone was initiated. On hospital day $6^{\text {th }}$, ceftriaxone was replaced with levofloxacin (500 $\mathrm{mg}$ intravenously once daily) due to the lack of response to the treatment. After three doses of levofloxacin, on the 8th day of hospitalization, the patient developed symptoms of neuroglycopenia with decreased capillary blood glucose to $30 \mathrm{mg} / \mathrm{dL}$. There was no deterioration in renal function (creatinine concentration and eGFR were $146 \mu \mathrm{mol} / \mathrm{L}$ and $25 \mathrm{~mL} / \mathrm{min} / 1.73 \mathrm{~m}^{2}$, respectively). Within following 8 hours, seven ampoules of $10 \mathrm{ml} 40 \%$ glucose injection and $1000 \mathrm{ml}$ of $5 \%$ glucose infusion were administered. Then, due to persistent tendency to hypoglycemia, a continuous intravenous infusion of $40 \%$ glucose at $10-50 \mathrm{~mL}$ per hour was begun. Glimepiride was discontinued. After 5 days of successful antibiotic treatment, levofloxacin was switched from intravenous to oral administration and then discontinued. Gradual normalization of glycemia was observed. On the $11^{\text {th }}$ hospital day intravenous glucose infusion was stopped. No further episodes of hypoglycemia were observed during the next days of hospitalization. After recovery, the treatment of diabetes was changed. Based on the current recommendation of Polish Diabetes Association and due to chronic kidney disease with final eGFR of $27 \mathrm{~mL} / \mathrm{min} / 1.73 \mathrm{~m}^{2}$ and persistently increased risk of hypoglycemia the therapy with glimepiride was changed to linagliptin $5 \mathrm{mg} / \mathrm{d}$.

\section{Discussion}

Levofloxacin is considered as a high effective and relatively safe fluoroquinolone antimicrobial used in the treatment of community-acquired pneumonia, complicated urinary tract infections and acute bacterial sinusitis [1-3]. Hypoglycemia secondary to levofloxacin is a rare complication $(<0,1 \%)$, but can be more common among elderly patients, with type 2 diabetes (especially treated with hypoglycemic drugs) or renal dysfunction [2]. Our patient was at high risk due to age, diabetes and chronic kidney disease. In the Naranjo probability scale, the patient scored 5 points, which indicates that hypoglycemia was a probable levofloxacin-related adverse effect (Tab. 1) [8].

The mechanisms underlying levofloxacin-induced hypoglycemia in diabetic patients are not fully understood. There is increasing evidence that they are related to drug-drug interactions [9] or hyperinsulinemia [10]. It is postulated that there are two main pathomechanisms that may lead to fluoroquinolone-induced hypoglycemia: pharmacokinetic and pharmacodynamic [9-12]. 
The first one is associated with competitive metabolism of levofloxacin and sulfonylureas by cytochrome P450 2C9 (CYP2C9) [9-12]. Pharmacodynamic theory is based on presumed fluoroquinolone-induced increase in insulin release from pancreatic beta-cells [11]. Levofloxacin inhibits ATP-sensitive potassium channels causing depolarization of the beta-cell membrane, which results in opening voltage-dependent calcium channels and insulin secretion [11]. Other experimental studies using rat islet cells suggest that fluoroquinolones act not as initiators but rather as augmenters of stimulated insulin release from beta-cells [12]. Of the three fluoroquinolones examined in the study with mouse pancreatic islets, levofloxacin appeared to be less likely to cause hypoglycemia than temafloxacin and gatifloxacin (both withdrawn from the market because of side effects, including hypoglycemia) [11]. However, in another study on rats, levofloxacin significantly affected glucose serum concentration in a dose-dependent manner [13].

Awareness about levofloxacin-induced hypoglycemia among physicians is relatively low. In a survey conducted in one of the university-affiliated teaching hospital, $80.4 \%$ of respondents were unaware about this adverse effect [4]. Importantly, this result may be underestimated due to a fatal case of levofloxacin-related hypoglycemia in this hospital, shortly before the questionnaire was conducted [4].

Clinical conditions to consider in the differential diagnosis of hypoglycemia in our patient include the following: chronic kidney disease, malnutrition, hypoglycemic effect of glimepiride, and less frequently - hyperthyroidism.

The patient had a long history of chronic kidney disease, with no episodes of hypoglycemia in the past. We also found no deterioration in renal function during hospitalization. Another cause of hypoglycemia might be malnutrition. However, during the patient's stay in hospital, her nutritional status was good and she weighed approximately 60 kilograms. Glimepiride, which was used by the patient, may also induce hypoglycemia, however we have no reports of hypoglycemia episodes in the past medical history of the patient. In addition, despite the use of glimepiride during hospitalization, blood glucose levels were normal until levofloxacin was included. Finally, hypoglycemia may have been a rare but possible complication of hyperthyroidism. It is well known that increased thyroid hormone levels are conducive to carbohydrate metabolism disorders. Importantly, hyperthyroidism usually predisposes to hyperglycemia, due to intensified he- patic gluconeogenesis, insulin resistance and increased glucose absorption from the gastrointestinal tract. An additional argument against hyperthyroidism-induced hypoglycemia is that the patient was in euthyroid state during hospitalization.

In conclusion, we suggest that levofloxacin should be used with greater caution, particularly in patients at increased risk of hypoglycemia.

\section{Conflict of interest}

The above-mentioned authors declare that there is no conflict of interest.

\section{REFERENCES}

1. Anderson VR, Perry CM. Levofloxacin : a review of its use as a high-dose, short-course treatment for bacterial infection. Drugs. 2008; 68(4): 535-565, doi: 10.2165/00003495-20086804000011, indexed in Pubmed: 18318569.

2. Levofloxacin Leaflet. Actavis Polska.

3. European Medicines Agency. Quinolone- and fluoroquinolonecontaining medicinal products. https://www.ema.europa.eu/en/ /medicines/human/referrals/quinolone-fluoroquinolone-containing-medicinal-products. Accessed 30 Nov 2019.

4. Singh N, Jacob JJ. Levofloxacin and hypoglycemia. Clin Infect Dis. 2008; 46(7): 1127, doi: 10.1086/529393, indexed in Pubmed: 18444840 .

5. Friedrich LV, Dougherty R. Fatal hypoglycemia associated with levofloxacin. Pharmacotherapy. 2004; 24(12): 1807-1812, doi: 10.1592/phco.24.17.1807.52348, indexed in Pubmed: 15585448.

6. Garber SM, Pound MW, Miller SM. Hypoglycemia associated with the use of levofloxacin. Am J Health Syst Pharm. 2009; 66(11): 1014-1019, doi: 10.2146/ajhp080105, indexed in Pubmed: 19451612.

7. Bansal N, Manocha D, Madhira B. Life-threatening metabolic coma caused by levofloxacin. Am J Ther. 2015; 22(2): e48-e51, doi: 10.1097/MJT.0b013e31829ed212, indexed in Pubmed: 23896743.

8. Busto U, Naranjo CA, Sellers EM, et al. A method for estimating the probability of adverse drug reactions. Clin Pharmacol Ther. 1981; 30(2): 239-245, doi: 10.1038/clpt.1981.154, indexed in Pubmed: 7249508.

9. Berhe A, Russom M, Bahran F, et al. Ciprofloxacin and risk of hypolycemia in non-diabetic patients. J Med Case Rep. 2019; 13(1): 142, doi: 10.1186/s13256-019-2083-y, indexed in Pubmed: 31078137.

10. Kelesidis T, Canseco E. Quinolone-induced hypoglycemia: a life-threatening but potentially reversible side effect. Am J Med. 2010; 123(2): e5-e6, doi: 10.1016/j.amjmed.2009.07.022, indexed in Pubmed: 20103009.

11. Saraya A, Yokokura M, Gonoi T, et al. Effects of fluoroquinolones on insulin secretion and beta-cell ATP-sensitive $\mathrm{K}+$ channels. Eur J Pharmacol. 2004; 497(1): 111-117, doi: 10.1016/j. ejphar.2004.06.032, indexed in Pubmed: 15321742.

12. Ghaly $H$, Kriete $C$, Sahin S, et al. The insulinotropic effect of fluoroquinolones. Biochem Pharmacol. 2009; 77(6): 1040-1052, doi: 10.1016/j.bcp.2008.11.019, indexed in Pubmed: 19073153.

13. Ishiwata $Y$, Itoga $Y$, Yasuhara M. Effect of levofloxacin on serum glucose concentration in rats. Eur J Pharmacol. 2006; 551(1-3): 168-174, doi: 10.1016/j.ejphar.2006.08.081, indexed in Pubmed: 17026994. 